\title{
Determinant of overweight and obesity among females' adolescents in the Eastern Province of Saudi Arabia, Cross-Sectional Study
}

Mona Faisal Al-Qahtani

Imam Abdulrahman Bin Faisal University

Azhar Ibrahim Alghareeb

Imam Abdulrahman Bin Faisal University

Zainab Sami Alramadan

Imam Abdulrahman Bin Faisal University

Mohamed Saleh Ismail ( $\square$ mohamed.ismail@hec.menofia.edu.eg )

Menoufia University https://orcid.org/0000-0002-5012-1404

\section{Research}

Keywords: BMI, French fries, Potato Chips, Donuts, ATLS

Posted Date: December 30th, 2019

DOI: https://doi.org/10.21203/rs.2.19650/v1

License: (c) (i) This work is licensed under a Creative Commons Attribution 4.0 International License. Read Full License 


\section{Abstract}

Background: several lifestyle factors related to adolescent overweight and obesity have been well documented. The main objectives of this study were to explore the common lifestyle behaviors among female adolescents based on body BMI category and to examine the association between overweight/obesity and lifestyle factors among them.

Methods: cross-sectional study was carried out on 598 participants, and Arab Teens Lifestyle Study (ATLS) questionnaire was used. Data related to lifestyle factors, e.g., physical activity, metabolic equivalent rate, sedentary behavior; dietary consumption; and anthropometrics including height, weight, and BMI were collected. To test the correlations between BMI and lifestyle factors, ANOVA and logistic regression were performed.

Results: based on BMI, $20.6 \%$ and $19.4 \%$ of females suffer from overweight and obesity, respectively. Results indicated significant differences $(P<0.05)$ in several female anthropometric factors and lifestyle behaviors based on BMI category. These factors comprised BMI, weight, consumption of French fries/potato chips, vegetables, fruits, and cake/donuts; and MET-min of swimming, and total physical activity (MET-min/week). Overweight/obesity was significantly associated with the consumption of cake/donuts (odds ratio [OR] for $>5$ days $/$ weeks $=2.261 ; 95 \%$ confidence interval $[\mathrm{Cl}]=1.361-3.757$ ), French fries (OR for 3-4 days/weeks=1.936; 95\% Cl=.206-3.110) and fruit (OR for 3-4 days/weeks=1.669; $95 \% \mathrm{Cl}=1.032-2.697)$.

Conclusion: a significant positive association between BMI category and factors such as eating French fries/potato chips and cakes/donuts were observed among adolescent Saudi females.

\section{Background}

Adolescence is considered a high-risk stage for changes in body weight, as it is a period of developmental plasticity [1, 2]. It was estimated that in 2010, 35 million adolescents and children in developing countries were overweight and obese [3]. The adverse physical consequences of child and adolescent obesity include an increase in cardiovascular risk factors, such as dyslipidemia, hypertension, hyperinsulinemia and impaired glucose tolerance [4]. Female adolescents are most vulnerable to the risk of obesity or weight gain because of consequent maternity-related obesity and unfavorable pregnancy outcomes. Surplus weight acquired during adolescence frequently persists throughout adulthood and is compounded during the childbearing period [5]. Several lifestyle factors related to adolescent overweight and obesity have been well documented. For example, it has been documented that physical activity (PA) is inversely related to body mass index (BMI). Levels of PA have been shown to decrease during adolescence, making this time a significant life period on which research should be focused [2]. Numerous lifestyle factors, for example, healthy dietary choices, PA, sleep duration, vigorous physical activity (VPA), and moderate to vigorous physical activity (MVPA), are significant correlates of adolescent BMI [6]. A Chinese study conducted on children and adolescents between 5 and 18 years old found that 
the prevalence rates of obesity and overweight were $6.4 \%$ and $15.3 \%$, respectively, and male were more commonly obese ( $9.5 \%$ vs. $3.1 \%$ ) or overweight compared to female (17.5\% vs. $12.9 \%)$ respectively [7].

Al-Hazzaa et al. [6] observed Arab adolescents aged 14 to 19 years and found that female adolescents were at a greater risk of inactivity and sedentary behavior than males were [8]. Multivariate logistic regression analyses of 868 children and adolescents aged 6-19 years in Lebanon showed that sedentary behavior and increased intake of sugar-sweetened drinks and fast food were correlated with an amplified risk of overweight, obesity, and abdominal adiposity, while consistent breakfast intake and increased consumption of dairy and added fats and oils were among the elements related to a reduced risk [9]. Additionally, Al-Hazzaa et al. [6] assessed how lifestyle factors affect the weight of adolescents aged 1419 years in 3 main cities in the Kingdom of Saudi Arabia. Among all of the lifestyle elements measured, obesity and overweight were significantly related to a low frequency of vigorous PA and infrequent intake of vegetables, sugar-sweetened beverages, and breakfast. In the Kingdom of Saudi Arabia, a nation that has undergone rapid urbanization and nutritional changes in recent decades, it is estimated that $10.6 \%$ and $26.6 \%$ of adolescents between the ages of 13 and 18 years are obese or overweight, respectively [6]. According to national data, in the Kingdom of Saudi Arabia, the prevalence of obesity was $\geq 10 \%$ greater among males than among females, while the prevalence of overweight was $\geq 10 \%$ greater among females [10-12].

The main objectives were as follows:

1 - To explore the most common lifestyle behaviours among female adolescents aged 12-16 years based on the WHO's BMI classification.

2 - To examine whether there are possible associations between lifestyle factors and BMI status.

\section{Methods}

\section{Research design}

This investigation was a cross-sectional quantitative study.

\section{Study setting}

This survey was conducted at 5 intermediate schools in the Eastern Province of Saudi Arabia.

\section{Participants}

Ten governmental schools had been proposed by the Directorate of General Education of the Eastern Province - Dammam - Female Section to take part in this study. Five out of the ten schools were selected by convenience sampling.

The five schools were informed by the Directorate of General Education at Eastern Province - Dammam about the times and days of the month when the researchers would visit. Then, these five schools 
randomly selected a number of classes for data collection. The questionnaires were given to all students in each of the selected classes. There were 604 females aged 12-16 years.

\section{Inclusion criteria}

1 - Adolescent female students at intermediate schools in the Eastern Province.

2 - Aged 12 to 16 years.

\section{Exclusion criteria}

1 - Any adolescent female students at intermediate schools in the Eastern province with physical disabilities.

\section{Data collection methods}

\section{Questionnaire}

The data were collected using a pre-validated questionnaire, the Arab Teens Lifestyle Study (ATLS), developed by Al-Hazzaa et al. [13]. This instrument was selected due to its demonstrated satisfactory validity. The ATLS is a self-reported questionnaire that includes 47 questions classified into 4 parts. The first part contains 5 items representing demographic data, such as age, height, weight, and year in school; the second part contains 26 items related to PA; the third part contains 6 items related to sedentary activities; the last part contains 10 items related to food consumption. All questions had multiple-choice answers in a logical order. In this study, all questionnaire data were recorded by participants except height and weight, which were measured and recorded by trained researchers. A pilot study was conducted on 37 students to determine the extent of clarity and acceptance of the questionnaire. The results of the pilot study indicated that the questionnaires were clear and did not contain any ambiguous language. The pilot study was conducted at one of the target schools, and the subjects in the pilot study were excluded from the main study.

\section{Measurements of physical activity (PA)}

Participants' PA was calculated based on the method presented by Al-Hazzaa et al. [13] in the ATLS questionnaire. This PA questionnaire included domains such as fitness and sports, transport and household activities. The PA was given metabolic equivalent of task (MET) values according to the compendium of PA and that of PA for young people.

The moderate-intensity PA examined in this study comprised recreational swimming, brisk walking, normal-pace walking, moderate-intensity recreational sports (for example, table tennis and volleyball), and household activities. These activities had MET values of 3-6 $[13,14]$. The vigorous PA considered in this study included cycling, jogging, stair climbing, self-defense, weight training and vigorous sports (for example, singles tennis, handball, soccer, and basketball). These activities had MET values of more than 
6 [13]. To quantify students' degrees of PA, we considered the total METs-min per week and the METs-min per week in performing the PA at moderate and vigorous intensity levels.

\section{Anthropometric parameters}

Students' weight (to the nearest $0.1 \mathrm{~kg}$ ) and height (to the nearest $0.5 \mathrm{~cm}$ ) were both assessed utilizing a stadiometer scale. The participants were wearing lightweight clothes and were asked to take off their shoes. The scale used to measure the participants' body weight (kilograms) was recalibrated to zero before each weighing. The height of each subject was also assessed after the weight measurement, and both height and weight were utilized to calculate the BMI of the female adolescents. The BMI categories being defined according to the standard BMI-for-age classification (i.e., thin, normal, overweight, and obese) for girls aged 5-19 years [15].

\section{Eating habits and food consumption}

The ATLS survey contains ten items intended to determine teenagers' habitual consumption of specific foods. The items reflect how many days per week a subject consumes sugar-sweetened drinks, breakfast, fruits, vegetables, milk and dairy foodstuffs, sweets (for example candy, cake, chocolate, and donuts), fast foods, and energy drinks. These items are able to capture a range of healthy and unhealthy nutritional habits. Possible responses ranged from 0 to extreme consumption of 7 days/week.

\section{Statistical analysis}

Age and sex, the major two confounders has been controlled as the age of all participants were ranged from 12 to 16 years old, and all of participants were females.

The Statistical Package for the Social Sciences (SPSS) version 23.0 (IBM, Chicago, Illinois, USA) was utilized for statistical analysis. Frequency and percentage were calculated as descriptive statistics. Inferential analysis was performed by ANOVA to determine whether there were any significant differences in female lifestyle factors based on BMI classes. Logistic regression was performed to explore the correlations between BMI category and lifestyle elements. BMI category was the dependent variable, while the independent variables were lifestyle factors, age, body weight, body height, sedentary activities, $\mathrm{PA}$, and food consumption.

The data were entered into a computer using the ATLS questionnaire computerization codes. For the PA data, METs-min was measured based on MET values provided by the WHO (shown in appendix A). Sedentary behavior, defined as screen time, other technology use, and sleep, was recorded in hours per day. Food consumption data were measured based on number of days per week. The BMI data were sorted manually into four categories based on the WHO BMI chart. The categories were as follows: thinness (thinness + severely thinness, below -2 SD), normal weight (-2 SD to +1 SD), overweight (above +1 SD), and obese (obese + morbid obese, above +2 SD). 


\section{Results}

Overall, 604 female participants were involved in the current study. However, 6 questionnaires were excluded due to omission of essential data. The participants' characteristics are reported in Table 1. As shown in the table, the mean age of the subjects was $13.85 \pm 0.96$ years (between 12 and 16 years old), the mean body height was $153.84 \pm 8.79 \mathrm{~cm}$, the mean body weight was $53.68 \pm 15.25 \mathrm{~kg}$, and the mean BMI was $22.56 \pm 5.80 \mathrm{~kg} / \mathrm{m}^{2}$.

Table 1. The mean \pm SD of age and anthropometric measurements for participants

\begin{tabular}{|ll|}
\hline Variable & Females $(\mathbf{n}=\mathbf{5 9 8})$ \\
\hline Age (years) & $13.85 \pm 1.0$ \\
\hline Weight $(\mathrm{Kg})$ & $53.7 \pm 15.3$ \\
\hline Height $(\mathrm{cm})$ & $153.8 \pm 8.8$ \\
\hline $\mathrm{BMI}\left(\mathrm{kg} / \mathrm{m}^{2}\right)$ & $22.6 \pm 5.8$ \\
\hline
\end{tabular}

Table 2 shows that, according to the WHO [15] BMI classification, 3.5\% of subjects were underweight, $20.6 \%$ were overweight and $19.4 \%$ were obese. Only $56.6 \%$ of subjects had normal body weight.

Table 2. Frequency distribution of studied subjects according to BMI classes

\begin{tabular}{|lll|}
\hline BMI classification & Frequency & Percent \\
\hline Thinness (thinness + sever thinness) (less than - 2 SD) & 21 & 3.5 \\
\hline Normal (more than - 2SD up to less or equal 1SD) & 338 & 56.5 \\
\hline Overweight (more than 1SD) & 123 & 20.6 \\
\hline Obese(obese + morbid obese)(more than 2SD) & 116 & 19.4 \\
\hline Total & 598 & 100.0 \\
\hline
\end{tabular}

Table 3 shows the mean and standard deviation scores for demographic and lifestyle variables by BMI class. Table 3 also reports the results of the ANOVA for significant differences among participants based on BMI classifications in relation to lifestyle factors. The results showed significant variations $(P<0.05)$ in female lifestyle factors based on BMI classes; these lifestyle factors comprised weight, BMI, vegetable consumption, French fry and potato chip consumption, cake and donut consumption, energy drink consumption, MET-min/week of swimming, MET-min/week of household tasks, and total PA (MET$\mathrm{min}$ /week). Compared with normal-weight individuals, overweight and obese individuals appeared to have significantly $(P<0.05)$ reduced consumption of energy drinks, cake and donuts, French fries and potato chips. Additionally, overweight and obese individuals seemed to have significantly $(P<0.05)$ 
higher consumption of vegetables than normal-weight subjects, but underweight subjects had the highest vegetable consumption of any group. Moreover, overweight and obese individuals appeared to be significantly $(P<0.05)$ more involved than other BMI categories in household activities and swimming compared. Obese subjects appeared to be involved significantly $(P<0.05)$ more than other classes in physical activities in that they performed the greatest total number of MET-min/week. 
Table 3

Mean and SD for age, anthropometric indices, physical activity, screen time, and food consumption with regard to BMI category for studied subjects.

\begin{tabular}{|c|c|c|c|c|c|}
\hline \multirow[t]{2}{*}{ Variable } & \multicolumn{5}{|l|}{ Females } \\
\hline & Thinness & Normal & Overweight & Obese & $\begin{array}{l}p- \\
\text { value }\end{array}$ \\
\hline Age (years) & $13.9 \pm .9^{\mathrm{a}}$ & $\begin{array}{l}13.9 \pm 1.0 \\
a\end{array}$ & $13.9 \pm 1.0^{a}$ & $13.7 \pm .9^{a}$ & 0.553 \\
\hline Weight (kg) & $\begin{array}{l}32.9 \pm 4.1 \\
\text { a }\end{array}$ & $\begin{array}{l}45.7 \pm 6.9 \\
b\end{array}$ & $58.9 \pm 6.1^{c}$ & $\begin{array}{l}75.4 \pm \\
15.6^{d}\end{array}$ & 0.000 \\
\hline Height (cm) & $\begin{array}{l}150.2 \pm 7.0 \\
\mathrm{a}\end{array}$ & $\begin{array}{l}154.0 \pm \\
6.9^{b}\end{array}$ & $\begin{array}{l}154.4 \pm 6.2 \\
b\end{array}$ & $\begin{array}{l}154.4 \pm \\
9.0^{b}\end{array}$ & 0.095 \\
\hline BMI (kg/m2) & $\begin{array}{l}14.5 \pm 0.9 \\
\mathrm{a}\end{array}$ & $\begin{array}{l}19.2 \pm 2.0 \\
b\end{array}$ & $24.7 \pm 1.5^{c}$ & $\begin{array}{l}31.5 \pm 5.5 \\
d\end{array}$ & 0.000 \\
\hline $\begin{array}{l}\text { Screen time (i.e. TV viewing and } \\
\text { computer use) (hour/day) }\end{array}$ & $2.9 \pm 1.9^{a}$ & $2.8 \pm 2.1^{a}$ & $2.6 \pm 2.1^{a}$ & $2.8 \pm 2.1^{\mathrm{a}}$ & 0.477 \\
\hline $\begin{array}{l}\text { METs-min/week of Moderate } \\
\text {-intensity physical activity }\end{array}$ & $\begin{array}{l}150.5^{ \pm} \\
181.5^{\mathrm{a}}\end{array}$ & $\begin{array}{l}129.6 \pm \\
383.5^{a}\end{array}$ & $\begin{array}{l}164.6 \pm \\
392.3^{\text {a }}\end{array}$ & $\begin{array}{l}142.7 \pm \\
270.2^{a}\end{array}$ & 0.832 \\
\hline $\begin{array}{l}\text { METs-min/week of Vigorous } \\
\text {-intensity physical activity }\end{array}$ & $\begin{array}{l}397.0 \pm \\
717.9 \mathrm{ab}\end{array}$ & $\begin{array}{l}225.1 \pm \\
584.2^{a}\end{array}$ & $\begin{array}{l}446.0 \pm \\
1335.6^{b}\end{array}$ & $\begin{array}{l}272.7 \pm \\
547.2 \mathrm{ab}\end{array}$ & 0.062 \\
\hline Total METs-min/week & $\begin{array}{l}3503.0 \pm \\
3484.1^{\mathrm{ab}}\end{array}$ & $\begin{array}{l}2386.4 \pm \\
2808.2^{a}\end{array}$ & $\begin{array}{l}3379.6 \pm \\
4566.3^{b}\end{array}$ & $\begin{array}{l}3691.0 \pm \\
4552.7^{b}\end{array}$ & 0.002 \\
\hline $\begin{array}{l}\text { Breakfast consumption } \\
\text { (frequency/week) }\end{array}$ & $4.3 \pm 2.7^{a}$ & $3.2 \pm 2.7^{\mathrm{a}}$ & $3.1 \pm 2.5^{\mathrm{a}}$ & $3.5 \pm 2.7^{\mathrm{a}}$ & 0.239 \\
\hline $\begin{array}{l}\text { Vegetables Consumption } \\
\text { (frequency/week) }\end{array}$ & $3.6 \pm 2.7^{a b}$ & $3.3 \pm 2.5^{\mathrm{a}}$ & $4.1 \pm 2.5^{b}$ & $3.4 \pm 2.5^{\mathrm{a}}$ & 0.018 \\
\hline $\begin{array}{l}\text { Fruits } \\
\text { Consumption(frequency/week) }\end{array}$ & $3.6 \pm 2.3 \mathrm{ab}$ & $3.1 \pm 2.3^{a}$ & $3.6 \pm 2.3^{b}$ & $3.5 \pm 2.3^{b}$ & 0.054 \\
\hline $\begin{array}{l}\text { Milk/dairy products intake } \\
\text { (frequency/week) }\end{array}$ & $3.8 \pm 2.6^{a}$ & $3.2 \pm 2.4^{a}$ & $3.5 \pm 2.5^{a}$ & $3.5 \pm 2.4^{a}$ & 0.431 \\
\hline $\begin{array}{l}\text { Sugar-sweetened drinks } \\
\text { (frequency/week) }\end{array}$ & $3.6 \pm 2.4^{a}$ & $3.2 \pm 2.4^{\mathrm{a}}$ & $3.1 \pm 2.5^{\mathrm{a}}$ & $2.8 \pm 2.4^{a}$ & 0.413 \\
\hline
\end{tabular}

$P$ value calculated by ANOVA and follow up LSD test

Values subscribed with different letters in the same row showed significant differences between these values $(P<0.0 .5)$. 


\begin{tabular}{|c|c|c|c|c|c|}
\hline Variable & Females & & & & \\
\hline Fast foods (frequency/week) & $3.4 \pm 2.1^{a}$ & $\begin{array}{l}2.7 \pm 2.0 \\
a b\end{array}$ & $2.4 \pm 1.7^{b}$ & $2.4 \pm 1.9^{b}$ & 0.056 \\
\hline $\begin{array}{l}\text { French fries/potato chips } \\
\text { (frequency/week) }\end{array}$ & $4.0 \pm 2.6^{a}$ & $2.8 \pm 1.9^{b}$ & $2.3 \pm 1.8^{c}$ & $\begin{array}{l}2.5 \pm 2.1 \\
b c\end{array}$ & 0.001 \\
\hline Cake/donuts (frequency/week) & $\begin{array}{l}4.00 \pm 2.2 \\
a\end{array}$ & $3.1 \pm 2.2^{a}$ & $2.5 \pm 2.1^{b}$ & $2.5 \pm 2.1^{b}$ & 0.003 \\
\hline Sweets (frequency/week) & $3.9 \pm 2.8^{a}$ & $3.6 \pm 2.4^{a}$ & $3.5 \pm 2.4^{a}$ & $3.2 \pm 2.4^{\mathrm{a}}$ & 0.495 \\
\hline Energy drinks (frequency/week) & $1.7 \pm 2.1^{\mathrm{a}}$ & $0.9 \pm 1.6^{b}$ & $0.6 \pm 1.2^{b}$ & $0.7 \pm 1.4^{b}$ & 0.008 \\
\hline swimming METs-min/week & $\begin{array}{l}648.6 \pm \\
168.4^{\mathrm{a}}\end{array}$ & $\begin{array}{l}209.6 \pm \\
536.6^{b}\end{array}$ & $\begin{array}{l}404.6 \pm \\
1116.5^{b}\end{array}$ & $\begin{array}{l}400.4 \pm \\
945.5^{b}\end{array}$ & 0.010 \\
\hline House holding METs-min/week & $2.6 \pm 2.6 \mathrm{ab}$ & $3.0 \pm 2.6^{a}$ & $3.5 \pm 2.8^{b}$ & $\begin{array}{l}3.4 \pm 2.8 \\
\mathrm{ab}\end{array}$ & 0.029 \\
\hline \multicolumn{6}{|c|}{$P$ value calculated by ANOVA and follow up LSD test } \\
\hline \multicolumn{6}{|c|}{$\begin{array}{l}\text { Values subscribed with different letters in the same row showed significant differences between these } \\
\text { values }(P<0.0 .5) \text {. }\end{array}$} \\
\hline
\end{tabular}

Table 4 shows the results of logistic regression analysis. The coefficient $\beta$ revealed that the following health-related variables were significantly correlated with overweight and obesity: consuming fruit 3-4 days/week (odds ratio $[\mathrm{OR}]=1.669 ; 95 \%$ confidence interval $[\mathrm{Cl}]=1.032-2.697, \mathrm{P}=0.037$ ), eating French fries $3-4$ days/week $(\mathrm{OR}=1.936 ; 95 \% \mathrm{Cl}=1.206-3.110, \mathrm{P}=0.006)$, and consuming cake $>5$ days $/$ week $(\mathrm{OR}=2.261 ; 95 \% \mathrm{Cl}=1.361-3.757, \mathrm{P}=0.002)$. 
Table 4

Associations between lifestyle factors and overweight/obesity

\begin{tabular}{|c|c|c|c|c|c|}
\hline Model & $\beta$ & SEE & $\mathbf{P}$ & OR & $(95 \% \mathrm{Cl})$ \\
\hline \multicolumn{6}{|c|}{ Breakfast intake $\geq 5$ days/week } \\
\hline$<3$ days/week & -.141 & .201 & .483 & .868 & $(.585-1.288)$ \\
\hline 3-4 days/week & .035 & .277 & .901 & 1.035 & $(.602-1.780)$ \\
\hline \multicolumn{6}{|c|}{ Sugar intake $<5$ days/week } \\
\hline 3-4 days/week & .116 & .223 & .602 & 1.123 & $(.725-1.740)$ \\
\hline$\geq 5$ days/week & .013 & .239 & .958 & 1.013 & $(.634-1.618)$ \\
\hline \multicolumn{6}{|c|}{ Vegetable intake $\geq 5$ days/week } \\
\hline$<3$ days/week & .290 & .221 & .189 & 1.337 & $(.867-2.062)$ \\
\hline 3-4 days/week & .101 & .262 & .701 & 1.106 & $(.661-1.850)$ \\
\hline \multicolumn{6}{|c|}{ Fruits intake $\geq 5$ days/week } \\
\hline$<3$ days/week & .416 & .229 & .069 & 1.516 & $(.968-2.374)$ \\
\hline 3-4 days/week & .512 & .245 & $.037 \star$ & 1.669 & $(1.032-2.697)$ \\
\hline \multicolumn{6}{|c|}{ Milk intake $\geq 5$ days/week } \\
\hline$<3$ days/week & -.008 & .212 & .970 & .992 & $(.655-1.504)$ \\
\hline 3-4 days/week & -.178 & .255 & .485 & .837 & $(.508-1.379$ \\
\hline \multicolumn{6}{|c|}{ Fast food intake $<5$ days/week } \\
\hline 3-4 days/week & .107 & .228 & .637 & 1.113 & $(.712-1.741)$ \\
\hline$\geq 5$ days/week & .367 & .275 & .183 & 1.443 & $(.842-2.474)$ \\
\hline \multicolumn{6}{|c|}{ French fries' intake $<5$ days/week } \\
\hline 3-4 day/week & .661 & .242 & $.006^{\star \star}$ & 1.936 & $(1.206-3.110)$ \\
\hline$\geq 5$ days/week & .407 & .265 & .124 & 1.502 & $(.894-2.525)$ \\
\hline \multicolumn{6}{|c|}{ Cakes intake $<5$ days/week } \\
\hline 3-4 days/week & -.015 & .247 & .951 & .985 & $(.606-1.600)$ \\
\hline$\geq 5$ days/week & .816 & .259 & $.002^{\star \star}$ & 2.261 & $(1.361-3.757)$ \\
\hline Sweet intake $\leq 5$ & & & & & \\
\hline
\end{tabular}




\begin{tabular}{|llllll|}
\hline Model & $\boldsymbol{\beta}$ & SEE & $\mathrm{P}$ & OR & $(95 \% \mathrm{Cl})$ \\
\hline 3-4 day/week & -.137 & .249 & .582 & .872 & $(.535-1.421)$ \\
\hline$>5$ days/week & -.334 & .245 & .174 & .716 & $(.443-1.158)$ \\
\hline TV watching $\leq$ 2 hours/day & & & & & \\
\hline $2-5$ hours/day & -.031 & .198 & .876 & .970 & $(.658-1.428)$ \\
\hline$>5$ hours/day & -.165 & .280 & .557 & .848 & $(.490-1.469)$ \\
\hline Net using $\leq 2$ hours/day & & & & & \\
\hline 2-5 hours/day & -.068 & .228 & .766 & .934 & $(.597-1.462)$ \\
\hline$>5$ days/week & -.394 & .249 & .113 & .674 & $(.414-1.097)$ \\
\hline Constant & -.135 & .275 & .624 & .874 & \\
\hline * $P<0.05$, and ** $P<0.01$ & & & & & \\
\hline
\end{tabular}

\section{Discussion}

The main objectives of the current study were to explore the most common lifestyle behaviors associated with WHO [15] BMI categories among female adolescents aged 12-16 years and to examine possible correlations of overweight and obesity with lifestyle factors. The main result of the current study is the presence of significant differences in female lifestyle behaviors, mainly weight, vegetable consumption, fruit consumption, French fries and potato chip consumption, cake and donuts consumption, energy drink consumption, MET-min of swimming, and total PA (MET-min/week), among different BMI classes.

Regression analysis revealed that female adolescents had increased odds of being overweight/obese if they consumed fruit 3-4 days per week, consumed French fries 3-4 days per week and/or consumed cake/donuts $>5$ days per week. Consumption of fruit only $3-4$ days per week may be insufficient to maintain a balanced diet. The recommended daily intake of fruits and vegetables is $\geq 5$ portions $[16,17]$. According to Styne et al. [16] and Spear et al. [17], lifestyle modification is suggested as a first-line treatment approach for reducing childhood obesity. This approach includes increasing the consumption of fruit and vegetables, engaging in continuous PA, altering dietary intake, adopting healthy dietary habits, and decreasing the daily time allocated for using computers and viewing TV.

The current study indicated that overweight/obesity was correlated with consumption of cake/donuts $>5$ days/week and intake of French fries 3-4 days per week. In terms of BMI classification for adolescent females, these results were nearly equivalent to the results published by Al-Hazzaa et al. [6].

The results of the current study indicated that the screen time ranged between 2.6 and 2.9 hours per day, which exceeded the maximum of 2 hours per day recommended by the guidelines of Canadian Sedentary Behavior Research for adolescents 12-17 years of age [18]. 
The literature highlights the association between sedentary behavior such as screen viewing time and overweight and obesity in adolescents [19]. However, very few studies carried out in countries other than Saudi Arabia showed any significant relationship between overweight or obesity and screen time. Although the mean screen time of overweight/obese adolescent Saudi females aged 15 to 17 in the study by Al-Hazzaa et al. [6] was more than twice ( 6.5 vs $2.7 \mathrm{hr}$./day) the amount observed in the current study, their results support the absence of a significant association between overweight/obesity and screen time among adolescent Saudi females, which is in agreement with the results of the current study. This lack of association may be a general trend among this group in Saudi Arabia.

In the study by Al-Hazza et al. [6], overweight/obesity was correlated with low PA levels. The findings of that study highlight the significant role of PA (mainly at a vigorous level) in preventing obesity among teenagers. The results of the current study are in accordance with such growing evidence that PA is a major issue in obesity throughout childhood and adolescence.

The relationship between screen time and overweight/obesity may be explained by the possibility that screen time displaces PA time, increases calorie consumption and diminishes resting metabolism [20].

The results from a cross-sectional study of 10- to 16-year-old adolescents in 34 countries showed that overweight adolescents had lower PA levels and spent more time watching TV than normal-weight adolescents did [21].

A study on a group of 11- to 15-year-old adolescents from the United States revealed that overweight was significantly related to vigorous PA but not moderate-intensity PA. Moreover, a significant negative relationship was noted between vigorous PA and total body fat among Spanish individuals [22].

Furthermore, a study of the impact of PA on obesity in a population aged 5-18 years revealed that more time allocated to vigorous PA resulted in a decline in obesity and an increase in aerobic capacity [23].

It seems that not all screen-based activities have equivalent relationships with adolescent overweight or obesity; a study carried out on Australian adolescents revealed that video games and computer use were not major risk factors for overweight and obesity [24].

Of all nutritional habits measured in the current study, the factors that significantly increased the odds of overweight and obesity were infrequent intake of fruit and high weekly consumption of French fries, potato chips, cake, and donuts. The findings of this study agreed with those of previous studies. Certainly, missing breakfast is a major predictor of overweight and obesity among adolescents from numerous countries $[25,26]$. Nevertheless, in Canadian adolescents, no obvious relationship between overweight/obesity and nutritional habits was observed [27]. The present study found that there was no significant inverse relationship between frequent intake of sugar-sweetened drinks and measures of overweight or obesity. This finding disagrees with other studies, which have stated that high intake of sugar-sweetened drinks is correlated with obesity in children [28]. 


\section{Conclusions}

This study determined the association of BMI with several lifestyle variables among female Saudi adolescents aged 12-16 years. A significant positive association was found between BMI category and factors such as intake of potato chips and French fries and frequent consumption of cake/donuts. In addition, overweight and obese subjects consumed fruit on fewer days per week than normal-weight subjects did. Primary prevention is needed in the form of a healthy diet and physical activity in adolescence, which can diminish the risk of obesity and support females in attaining a healthier body composition prior before they progress to childbearing age.

\section{Recommendations}

1 - School cafeterias should provide healthier food items than they currently do.

2 - Parents' awareness of obesity and its risk factors, as well as healthy adolescent lifestyles, should be increased.

3 - Girls' intermediate schools should provide mandatory physical education classes.

4 - We suggest school educational interventions to promote healthy lifestyle behavior.

5 - Schools must provide infrastructure that allows the students to engage in PA.

6 - Adolescents should be encouraged to adopt a healthy lifestyle in all aspects.

\section{Supporting information}

Title: METs values based on WHO 


\begin{tabular}{|lll|}
\hline ACTIVITY & MET value & Formula \\
\hline moderate walking & 2.5 & Frequency* $2.5+$ minutes \\
\hline brisk walking & 3.3 & Frequency* $3.3+$ minutes \\
\hline jogging \& running & 8 & Frequency* $8+$ minutes \\
\hline cycling & 7 & Frequency* $7+$ minutes \\
\hline swimming & 6 & Frequency* $6+$ minutes \\
\hline moderate intensity sports & 4 & Frequency* $4+$ minutes \\
\hline vigorous-intensity sports & 8 & Frequency* $8+$ minutes \\
\hline self-defense & 7 & Frequency* $7+$ minutes \\
\hline weight training (resistance training or calisthenics) & 6 & Frequency* $6+$ minutes \\
\hline household activity & 3 & Frequency* $3+$ minutes \\
\hline Dancing & 5.5 & Frequency* $5.5+$ minutes \\
\hline stair steps & 8 & Frequency $3 * 8+$ minutes \\
\hline
\end{tabular}

\section{Abbreviations}

ATLS: The Arab Teens Lifestyle Study

MET: Metabolic Equivalent of Task

OR: Odds Ratio

Cl: Confidence Interval

PA: Physical Activity

VPA: Vigorous Physical Activity

MVPA: Moderate to Vigorous Physical Activity

\section{Declarations}

\section{Limitation of the study.}

One of the main limitations is that all the participants in this study were female adolescents. Therefore, we recommend the inclusion of male students in future studies to allow comparison of BMI-related factors between genders. 
This research was ethically approved by an Institutional Review Board (IRB) at Imam Abdulrahman Bin Faisal University (IRB-UGS-2018-03-041). A second approval was obtained from the Directorate of General Education at Eastern Province - Dammam - Female Section for data collection in intermediate schools in the Eastern State.

The research idea, objectives, and data integrity and security measures had been explained to the participants, and verbal consent was secured from the participants and their parents. All participants were also assured that they had the right to withdraw from the study at any time.

\section{Consent for publication}

Not applicable.

\section{Availability of data and materials}

The datasets used and/or analyzed during the current study are available from the corresponding author on reasonable request.

\section{Competing interests}

The authors declare to have no competing interests.

\section{Funding}

This study didn't receive any financial support or funds

\section{Authors' contributions}

1. Al-Qahtani and M. Ismail designed the study; M. Al-Qahtani, A. Alghareeb and Z. Alramadan performed the study and collect the data; M. Al-Qahtani analyzed the data; M. Ismail and M. AlQahtani wrote the paper.

\section{Acknowledgements}

The authors acknowledges the Institutional Review Board of Imam Abdulrahman Bin Faisal University, Dammam, Kingdom of Saudi Arabia for their approval of the current study. We also, thank all the students for their valuable participation in the study. We would like to express deep thanks to our trained researchers, Shrifah Al-Khalaf and Raghad AlHotheyfa, for their assistance in taking the anthropometric indices. The authors have no conflict of interest.

\section{References}

1- Hochberg Ze, Belsky J. Evo-devo of human adolescence: beyond disease models of early puberty. BMC Medicine. 2013;11(113):11. doi.org/10.1186/1741-7015-11-113 
2- lyer I, Burroughs A, Anand S, de Souza R, Aravind L. Polyvalent Proteins, a Pervasive Theme in the Intergenomic Biological Conflicts of Bacteriophages and Conjugative Elements. Journal of Bacteriology. 2017;199(15). doi: 10.1128/JB.00245-17

3- WHO. Population-based prevention strategy-genes for childhood obesity. Geneva: WHO Press. Available from: https://www.who.int/dietphysicalactivity/childhood/approaches/en/

4- Zalbahar $\mathrm{N}$. The association between parental overweight and obesity before pregnancy and the development of offspring overweight and obesity in childhood, adolescence and young adulthood: The University of Queensland; 2017. doi: 10.14264 / uql.2017.562.

5- Todd A, Street S, Ziviani J, Byrne N, Hills A. Overweight and Obese Adolescent Girls: The Importance of Promoting Sensible Eating and Activity Behaviors from the Start of the Adolescent Period. International Journal of Environmental Research and Public Health. 2015;12(2):23. doi: 10.3390/ijerph120202306.

6- Al-Hazzaa H, Abahussain N, Al-Sobayel H, Qahwaji D, Musaiger A. Lifestyle factors associated with overweight and obesity among Saudi adolescents. BMC Public Health. 2012;12(354):1-11. .doi: 10.1186 / 1471-2458-12-354.

7- D'Addesa D, D'Addezio L, Martone D, Censi L, Scanu A, Cairella G, et al. Dietary Intake and Physical Activity of Normal Weight and Overweight/Obese Adolescents International Journal of Paediatrics 2010;2010. doi: 10.1155/2010/785649.

8- Al-Hazzaa HM. Lifestyle Behaviors and Obesity: Brief Observations from the Arab Teens Lifestyle Study (ATLS) Findings. Obesity Open Access. 2018;4(1). doi: 10.16966/2380-5528.136.

9- Nasreddine L, Naja F, Akl C, Chamieh MC, Karam S, Sibai A, et al. Dietary, Lifestyle and Socio-Economic Correlates of Overweight, Obesity and Central Adiposity in Lebanese Children and Adolescents. Nutrients. 2014;6(3):1038-62. doi: 10.3390/nu6031038.

10- El Mouzan MI, Foster PJ, BS. A, AA. A, Al Omer AA, Qurachi MM, et al. Prevalence of overweight and obesity in Saudi children and adolescents. Annals of Saudi Medicine. 2010;30(6):203-8. doi: 10.4103/0256-4947.62833.

11-Al-Mohaimeed A, Ismail M, Dandash K, Ahmed S, Al-Harbi M. Progressive changes in overweight and obesity during the early years of schooling among children in a central region of Saudi Arabia. Food and Public Health. 2012;2(5):159-67. doi: 10.5923/j.fph.20120205.07

12- Al-Muhaimeed AA, Dandash KM, Ismail MS, Saquib N. Prevalence and correlates of overweight status among Saudi school children. Ann Saudi Med. 2015;35(4):275-81. doi: 10.5144/0256-4947.2015.275.

13- Al-Hazzaa HM, Al-Sobayel H, Musaiger AO. Convergent Validity of the Arab Teens Lifestyle Study (ATLS) Physical Activity Questionnaire. Int J Environ Res Public Health. 2011;8(9):3810-20. doi: 10.3390/ijerph8093810. 
14- WHO, Growth reference 5-19 years- BMI-for-age (5-19 years) for girls. Available from: https://www.who.int/growthref/bmifa_girls_5_19years_z.pdf?ua=1

15- Styne DM, Arslanian SA, Connor EL, Farooqi ES, Murad H, Silverstein JH, et al. Pediatric ObesityAssessment, Treatment, and Prevention: An Endocrine Society Clinical Practice Guideline. J Clin Endocrinol Metab. 2017;102(3):709-57. doi: 10.1210/jc.2016-2573.

16- Spear BA, Barlow SE, Ervin C, Ludwig DS, Saelens BE, Schetzina KE, et al. Recommendations for Treatment of Child and Adolescent Overweight and Obesity. Pediatrics. 2007;120(Suppl 4):245.

17- Tremblay MS, Aubert S, Barnes JD, Saunders TJ, Carson V, Latimer-Cheung AE, et al. Sedentary Behavior Research Network (SBRN) - Terminology Consensus Project process and outcome. International Journal of Behavioral Nutrition and Physical Activity. 2017;14:75. doi.org/10.1186/s12966017-0525-8.

18- O'Brien W, Issartel J, Belton S. Relationship between Physical Activity, Screen Time and Weight Status among Young Adolescents. Sports (Basel). 2018;6(57). doi: 10.3390/sports6030057

19- Robinson TN, Hammer LD, Killen JD, Kraemer HC, Wilson DM, Hayward C, et al. Does television viewing increase obesity and reduce physical activity? Cross-sectional and longitudinal analyses among adolescent girls. Pediatrics. 1993;91(2):273-80.

20- Janssen I, Katzmarzyk PT, Boyce WF, Vereecken C, Mulvihill C, Roberts C, et al. Comparison of overweight and obesity prevalence in school-aged youth from 34 countries and their relationships with physical activity and dietary patterns. Obes Rev. 2005;6(2):123-32. doi: 10.1111 / j.1467789x.2005.00176.x.

21- Moliner-Urdiales D, Ruiz JR, Ortega FB, Rey-Lopez JP, Vicente-Rodriguez G, España-Romero V, et al. Association of objectively assessed physical activity with total and central body fat in Spanish adolescents; the HELENA Study. Int J Obes (Lond). 2009;33(10):1126-35. doi: 10.1038 / ijo.2009.139.

22- Parikh T, Stratton G. Influence of intensity of physical activity on adiposity and cardiorespiratory fitness in 5-18 year olds. Sports Med. 2011;41(6):477-88. doi: 10.2165 / 11588750-00000000-00000.

23- Burke V, Beilin LJ, Durkin K, Stritzke WG, Houghton S, Cameron CA. Television, computer use, physical activity, diet and fatness in Australian adolescents. Int J Pediatr Obes. 2006;1(4):248-55. doi: 10.1080 / 17477160600984975.

24- Deshmukh-Taskar PR, Nicklas TA, O'Neil CE, Keast DR, Radcliffe JD, Cho S. The relationship of breakfast skipping and type of breakfast consumption with nutrient intake and weight status in children and adolescents: The National Health and Nutrition Examination Survey 1999-2006. J Am Diet Assoc. 2010;110(6):869-78. doi: 10.1016 / j.jada.2010.03.023. 
25- Duncan S, Duncan EK, Fernandes RA, Buonani C, Bastos KD, Segatto AFM, et al. Modifiable risk factors for overweight and obesity in children and adolescents from São Paulo, Brazil. BMC Public Health. 2011;11:585. doi: 10.1186/1471-2458-11-585.

26 Janssen I, Katzmarzyk PT, Boyce WF, King MA, Pickett W. Overweight and obesity in Canadian adolescents and their associations with dietary habits and physical activity patterns. J Adolesc Health. 2004;35(5):360-7. doi: 10.1016 / s1054-139x (04) 00058-8.

27- Ludwig, D., Peterson, K., \& Gortmaker, S. Ludwig DS, Peterson KE, Gortmaker SL. Relation between consumption of sugar-sweetened drinks and childhood obesity: a prospective, observational analysis. Lancet. 2001;357(9255):505-8. doi: 10.1016 / s0140-6736 (00) 04041-1. 